\title{
Theory and Application of Tacit Knowledge Transfer
}

\author{
Jia-Cheng Chang1,2,3, Ding-Bang Luh², Shiann-Far Kung2 , Akira Ueda ${ }^{3}$ \\ ${ }^{1}$ Creative Product Design, Southern Taiwan University, Tainan City, Chinese Taipei \\ ${ }^{2}$ Institute of Creative Industries Design, National Cheng Kung University, Tainan City, Chinese Taipei \\ ${ }^{3}$ Design Culture Unit, Design Science Department, Graduate School of Engineering, Chiba University, Chiba, \\ Japan \\ Email: brysonchang@gmail.com
}

Received 12 September 2014; revised 6 October 2014; accepted 18 October 2014

Copyright (C) 2014 by authors and Scientific Research Publishing Inc.

This work is licensed under the Creative Commons Attribution International License (CC BY).

http://creativecommons.org/licenses/by/4.0/

(c) (i) Open Access

\section{Abstract}

Tacit knowledge, regarding its essence, is a kind of "understanding", comprehension, and the process of grasping and re-organizing experiences. Moreover, such ability can be controlled at will. However, spiritual understanding enables people to display the function of dominance and determination of knowledge. Therefore, this study first proposed the tacit knowledge transfer mode; there are two major strategies for the Tacit Knowledge Transfer Method (TKTM): depict the essence instead of the appearance and understand spiritually. In other words, it allows learners to represent the knowledge learned and transfer it into body memory in order to apply it to similar situations through deduction and inference. This study aims to integrate Tacit Knowledge Transfer Method (TKTM) into sketch instruction. The first phase was "knowledge accumulation": we used "Mu" way to accumulate drawing knowledge. The phase two was "knowledge transfer": we used "Lin" way to transfer drawing knowledge. In the process, the students in Department of Design are divided into the experimental group and the controlled group for comparisons. Having seven design experts evaluate the teaching effectiveness on the two groups (Mixed and anonymous), aiming at students' learning achievement. The experiment concludes two main results: firstly, based on the expert evaluation scores, Tacit Knowledge Transfer Method (TKTM) proves the significant effect of Tacit Knowledge Transfer Method (TKTM) on Perspective Accuracy, Line Stability, and Form Expressivity of freehand sketch; secondly, from the experiment process and survey results, it was evident that Tacit Knowledge Transfer Method (TKTM) has direct correlation with participants' assertiveness. If there is a conflict between norm knowledge the effectiveness of transfer will be reduced significantly.

\section{Keywords}

Component, Formatting, Style, Styling 


\section{Introduction}

Having taught for many years, the researchers have found that there is so much know-how that cannot be explained clearly in class, such as the tacit rules in daily life that cannot be explained explicitly with words. We understand much knowledge and take it for granted but it is rather difficult for us to search for an explicit method to express it, for example, hitting a golf ball with an iron club. Which angle should we take and how much force should be used to strike the ball with balancing hands in order to make it fly high and straight? It is similar to throwing a basketball. In addition to motion and force, we need to pay attention to the palms' feel and the fingers' touch.

Stewart (2003) explains that the term tacit, which was originated in Latin, means "to be silent or secret". Complimentary to explicit knowledge, tacit knowledge is the knowledge possessed by an individual that is not expressed and displayed. The word explicit also comes from Latin, meaning "to unfold", which includes manifestation, summarization, and explication. It almost implies "informatization". In Latin literature, medieval scholars tend to write the word "explicit" at the end, expressing that this paper is intended to be shared by the public. There is a wonderful German word "fingerspitzengefuhl" that means "a feeling in the fingertips," which works almost like the synonym of tacit knowledge". Most high-valued knowledge workers have sound tacit knowledge partly because much tacit knowledge is replaced by automation.

Nanaka believes that tacit knowledge is highly personalized and formalized; therefore, it is rather difficult to be communicated or shared, for example, subjective insight foretelling, and intuition (Nonaka, 2004). In addition, tacit knowledge is rooted deeply in people's actions and experiences as well as in people's ideals, values, and emotions. Basically speaking, it is the knowledge that is not "verbalized" and "articulated" yet, difficult to be described or explicated. In addition the possessor is unconscious of possessing such knowledge. Similar to learning new things, people may not need to be particularly concentrated or use much effort. Instead, they learn it in tacit manners. Reber (1993), a psychologist, suggests that the features connected to "implicit learning" include: 1) Tacit learning is the foundation of obtaining tacit knowledge and it is also the representative and summary of environment structure; 2) the best way of acquiring tacit knowledge is unconscious learning; and 3) Tacit knowledge can be used in problem solving and to make a reasonable judgment. The process of problem solving and judgment is tacit. Therefore, in design instruction there are various kinds of tacit knowledge worthy of further exploration and understanding. As educators, it is necessary for us to find out an effective method of in order to transfer tacit knowledge of design to the students, other than explicit knowledge, so that they can grasp the key of learning easily.

The concept of tacit knowledge originated from Michael Polanyi's philosophy. In 1966, he wrote "The tacit dimension” (Polanyi, 1967). In 1973, he wrote another essay "Personal knowledge”. According to Polanyi, tacit knowledge is different from formal and objective knowledge. Summarizing the concept, Polanyi writes, "We know more than we can tell". Tacit knowledge is rooted deeply in people and the society, closely related to symptoms, intuition, feeling, mindscape, and emotion. Being a kind of personal knowledge, it is rooted deeply in an individual's experience and conscious. Constituted by personal experience, values, and culture, it helps individuals to understand the knowledge of the meanings of the world. Therefore, it is highly influenced by personal belief and values.

In the product design field, the top ten factors in sketch composition contain 1) shape expression, 2) proportion accuracy, 3) prospective accuracy, 4) presentation from different angles, 5) color expression, 6) three-view drawing, 7) interface flow chart, 8) material expression, 9) exploded drawing, and 10) morphological change (Ou, 2008). In this study, the above factors are classified into three sketch professional competence indices, including Perspective Accuracy, Line Stability, and Form Expressivity. However, these three kinds of knowledge are the most difficult to be expressed clearly in the teaching of design and drafting, which are common indicators in the industry and the core of study. Therefore, we regard them as objects in the evaluation of students' accomplishments in learning and practices.

The transferal of knowledge is frequently seen in the training of artistic creation. For example, the teaching of calligraphy in ancient China was a kind of tacit knowledge transferal. Calligraphy is a performing art of writing as well as a plastic art. Calligraphy is mainly instructed through "imitation" (lin), and "copy" (mu) which are two different but complementary methods. Imitation is reproducing the essence of the writing. Meanwhile, copy is to mimic the form of the characters. A learner can imitate the essence of the art, and copy the form of writings. If a person imitates without copying, it is just like abandoning the use of the compass and ruler. If a person cop- 
ies without imitating, it is like eating the husk and leaving the rice behind. Both of them are not ideal ways of learning. Both "copy" and "imitation" are complementary ways of learning. Therefore, teachers in the ancient times required students to master both methods; therefore "copy" and "imitation" have been used together, becoming frequently used terms in calligraphy.

In this research, the methods of "Lin" and "Mu" in ancient Chinese calligraphy are studied to establish the system of Tacit Knowledge Transfer Method (TKTM) with the techniques of product design and expression as examples to conduct the experiment (Yi, 2006).

\section{Experiment Design}

In this experiment design, there are two major strategies regarding Tacit Knowledge Transfer Method (TKTM): First, it is the depiction of the essence instead of the appearance, i.e. tacit influence in knowledge. It is able to allow learners to re-present the memory tank of their bodies during their learning. Second, it is spiritual understanding, i.e. the liberal absorption and application of knowledge. It allows learners to re-present the knowledge learned and transfer it into body memory in order to apply it to similar situations by deduction and inference.

This study aims to discuss the sketch achievement of Tacit Knowledge Transfer Method (TKTM). Before the SSTM experiment, the research contents are planned as below.

1) Making product design simulation database.

2) Explaining the simulation learning flow to the participants in the experimental group.

3) Establishing a proper sketch evaluation standard as the evaluation basis of this study.

4) The experimental group is proceeded TKTM, while the controlled group remains present instruction. The research flow is shown in Figure 1.

\subsection{Experiment Participants}

The template is used to format your paper and style the text. All margins, column widths, line spaces, and text fonts are prescribed; please do not alter them. You may note peculiarities. For example, the head margin in this template measures proportionately more than is customary. This measurement and others are deliberate, using specifications that anticipate your paper as one part of the entire journals, and not as an independent document. Please do not revise any of the current designations.

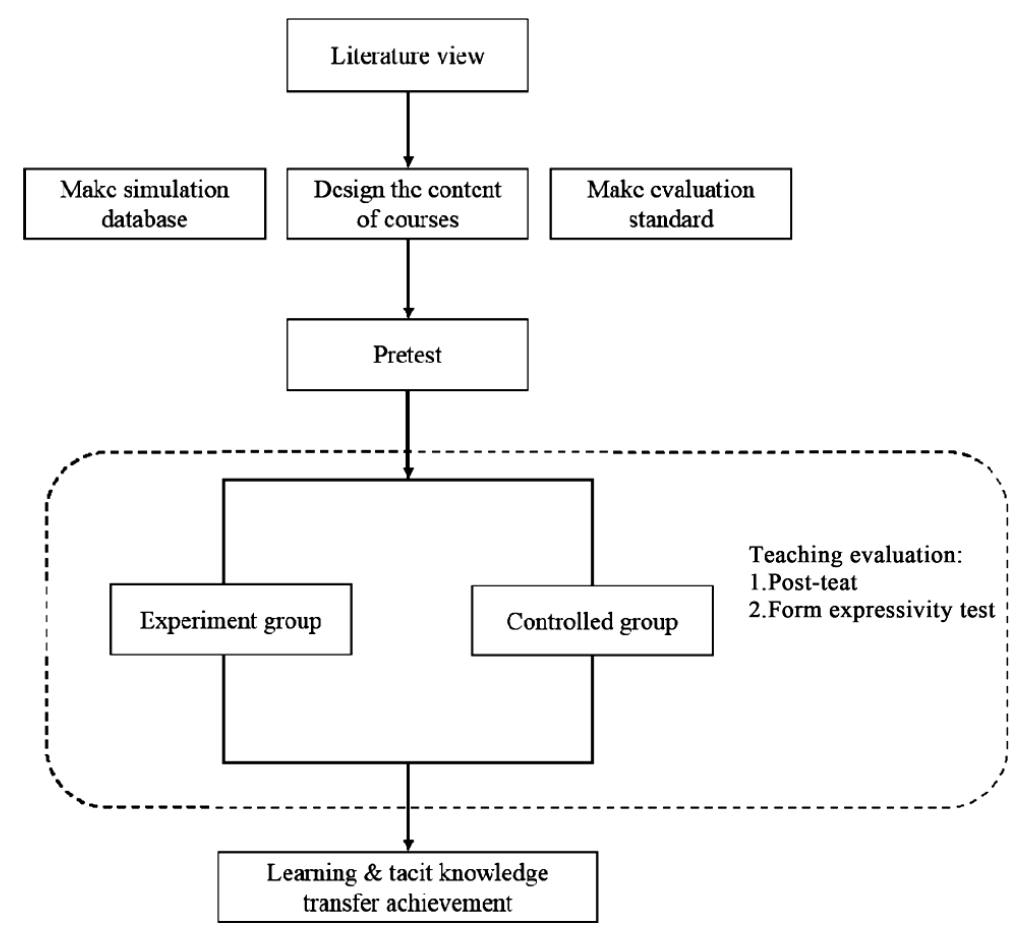

Figure 1. Research \& experiment flow. 
Drawing Skills for Design is selected as the experimental course, which is further divided into the experimental group (Group A) and the controlled group (Group B). Both the experimental group (Group A), with 24 students, and the controlled group (Group B), 22 students, are taught by the same instructor for twelve weeks. The experiment lasts for fourteen weeks, including the days for pretest and post-test.

\subsection{Independent Variable-Teaching Method}

1) The experimental group (Group A) is introduced GDP’ SSTM and the practice in the learning process.

2) The controlled group controlled group (Group B) applies current hand drawing to the instruction and practice.

\subsection{Dependent Variable}

1) Drawing tests of Perspective Accuracy.

2) Drawing tests of Line Stability.

3) Drawing tests of Form Expressivity.

\subsection{Control Variable}

1) Teaching contents and hours. Both the experimental group and the controlled group are taught the same contents with the same hours. The assignment quantity and contents are also identical.

2) Student aptitude and motivation. The participants are the freshmen in Department of Product Design who are randomly divided into the experimental group and the controlled group. The students in both groups are proceeded pretest and post-test by drawing the same topic. The progress between pretest and post-test is taken as the evaluation basis.

\subsection{Research Tool}

Based on famous design awards approved by International Council of Societies of Industrial Design (ICSID), including German IF (International Forum Design Hannover), German Red Dot Award, the US IDEA (Industrial Design Excellence Awards), and Japan G-Mark (Good Design Award), which are collectively called GDP, the awarded works in 2010-2012 are selected for the database and further used as the teaching materials, after discussing and revising with the instructor.

\subsection{Teaching Step}

The group with current teaching methods (Group B) is taught the prospective principles and the basic skills stays in the classroom. An object is drawn by the students every week, which is further explained, modified, and evaluated. The experimental group (Group A) is instructed GDP' SSTM and proceeds GDP' simulation practice after class. The instructor further explains, modifies, and evaluates such simulation works. The GDP' simulation practice follows the following steps as shown in Figure 2.

1) Step 1: Prepare a drawing paper.

2) Step 2: Observe the simulated product construction.

3) Step 3: Cover the drawing paper on the simulated GDP.

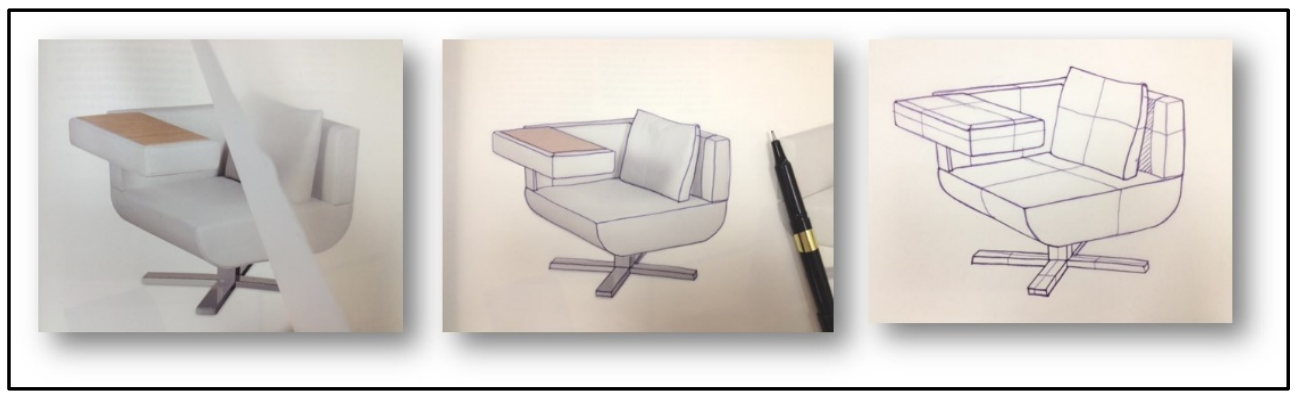

Figure 2. TKTM training step. 
4) Step 4: Precede simulation and draw the product.

5) Step 5: Complete the outline simulation.

6) Step 6: Observe the simulated product surface.

7) Step 7: Draw the construction line.

8) Step 8: Complete a single product simulation.

9) Step 9: The second phase, student needed draw product again on their own.

\subsection{Test}

Design Sketch test is developed by the researcher and the instructor. Aiming at the test, a pretest is preceded for draft revision. The development covers the processes of questioning, evaluating questions, and modifying. Returning the product to the basic geometric forms is questioned. A toaster, which is similar to a rectangular prism, is selected as the pretest and post-test topic. The instructor also assigns a topic for the students completing the sketches in a certain time.

\section{Evaluation Standard}

The drawing skill scale, as a general criterion, is organization by the researcher, aiming at existing literatures on freehand sketch and the interviews with seven experts who have more than ten years experiences in the field (Expert data is shown in Table 1). It is used for evaluating the students' freehand sketch skills in product design, including 1) Perspective Accuracy, 2) Line Stability, and 3) Form Expressivity. The marks are given 0 - 10; 0 stands for No progress (including lag), 1 for Slight progress but not much, and goes on till the highest 10.

\section{Analysis}

The participants were proceeded the teaching experiment. The course was divided into the experimental group (Group A) and the controlled group (Group B), and a toaster was taken as the sample for pretest and post-test. Figure 3 shows the sketch samples of the two groups.

\subsection{Kendall's W Test}

Perspective Accuracy, Line Stability, and Form Expressivity of freehand sketch were tested. Students' learning achievement of pretest and post-test were evaluated the progress. Based on the seven experts' evaluation, Kendall's W test was further proceeded (Table 2).

In Table 2, Perspective Accuracy, Line Stability, and Form Expressivity of freehand sketch in both groups achieved gradual significance $(p<0.05)$. Besides, $\mathrm{W}$ value in Kendall' $\mathrm{W}$ of both groups appeared in $0.6-0.7$, showing fair to high consistency of the seven experts' evaluation of the two groups.

\subsection{T-Test}

Teaching method was regarded as the independent variable, and the progress in Perspective Accuracy, Line Sta-

Table 1. Expert list.

\begin{tabular}{|c|c|c|c|}
\hline Code & Current position & Experience & Remark \\
\hline Expert 1 & $\begin{array}{l}\text { Creative Product Design, Southern Taiwan } \\
\text { University of Science and Technology/Lecturer }\end{array}$ & $\begin{array}{l}\text { Four years in instructing freehand } \\
\text { sketch, } 15 \text { years in design }\end{array}$ & Lecturer \\
\hline Expert 2 & Idea Creation Co., Ltd./Design Director & 12 years in design & Designer in business \\
\hline Expert 3 & Idea Creation Co., Ltd./Design Director & 11 years in design & Designer in business \\
\hline Expert 4 & NDD Design/Creative Director & 11 years in design & Designer in business \\
\hline Expert 5 & Lin Min Design/Chief Executive Officer & 13 years in design & Designer in business \\
\hline Expert 6 & Qisda Design Department/Senior designer & 15 years in design & Designer in business \\
\hline Expert 7 & Up Creative Design/R \& D Assistant Manager & 11 years in design & Designer in business \\
\hline
\end{tabular}




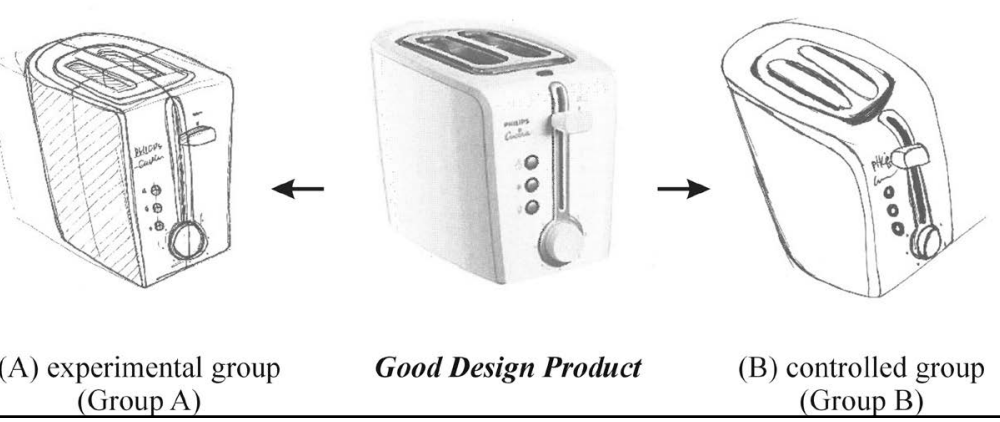

Figure 3. Sketch samples of the experimental group (Group A) and the controlled group (Group B).

Table 2. Kendall's W test result.

\begin{tabular}{|c|c|c|c|c|c|c|}
\hline \multirow{2}{*}{$\begin{array}{c}\begin{array}{c}\text { Sketch } \\
\text { competence }\end{array} \\
\text { Group }\end{array}$} & \multicolumn{2}{|c|}{ Sketch competence } & \multicolumn{2}{|c|}{ Sketch competence } & \multicolumn{2}{|c|}{ Sketch competence } \\
\hline & $\begin{array}{l}\text { The experimental } \\
\text { group }\end{array}$ & $\begin{array}{l}\text { The controlled } \\
\text { group }\end{array}$ & $\begin{array}{l}\text { The experimental } \\
\text { group }\end{array}$ & Group & $\begin{array}{l}\text { The experimental } \\
\text { group }\end{array}$ & $\begin{array}{l}\text { The controlled } \\
\text { group }\end{array}$ \\
\hline Number & 30 & 30 & 30 & 30 & 30 & 30 \\
\hline Kendall's W test & 0.659 & 0.611 & 0.657 & 0.643 & 0.691 & 0.756 \\
\hline Chi-square & 118.628 & 110.004 & 118.275 & 115.701 & 124.336 & 136.114 \\
\hline $\begin{array}{l}\text { Degree of } \\
\text { freedom }\end{array}$ & 6 & 6 & 6 & 6 & 6 & 6 \\
\hline $\begin{array}{c}\text { Gradual } \\
\text { significance }\end{array}$ & 0.000 & 0.000 & 0.000 & 0.000 & 0.000 & 0.000 \\
\hline
\end{tabular}

bility, and Form Expressivity as the dependent variable for Independent Sample T-test, in order to observe the learning achievement of the two groups (Table 3).

1) Transfer achievement of Perspective Accuracy of freehand sketch.

The learning achievement of Perspective Accuracy appeared F $=4.535$, not achieving the significance, showing the performance of both groups corresponding to the homogeneity of variance. From the significance generated from T-test, the progress of Perspective Accuracy revealed remarkable differences between the two groups $(p=0.000)$. Besides, $\mathrm{T}=12.263$ presented high differences between the two groups. In other words, the learning achievement of Perspective Accuracy of freehand sketch showed highly notable differences between the experimental group (Group A) and the controlled group (Group B).

2) Transfer achievement of Line Stability of freehand sketch.

The learning achievement of Line Stability showed F-test not reaching the significance, presenting the performance of both groups corresponding to the homogeneity of variance. The significance generated from T-test revealed remarkable differences in the progress of Line Stability between the two groups $(p<0.05)$, and $\mathrm{T}=$ 10.573 showed high differences between the two groups. In this case, the learning achievement of Line Stability of freehand sketch appeared highly notable differences between the experimental group (Group A) and the controlled group (Group B).

3) Transfer achievement of Form Expressivity of freehand sketch.

The learning achievement of Form Expressivity appeared F-test achieving the significance, showing the performance not corresponding to the homogeneity of variance. The significance generated from T-test presented significant differences in Form Expressivity between the two groups $(\mathrm{p}<0.05)$, and $\mathrm{T}=14.242$ showed high differences between the two groups. In other words, the learning achievement of Form Expressivity of freehand sketch appeared highly notable differences between the experimental group (Group A) and the controlled group (Group B).

\section{Discussion \& Conclusion}

After interviews and homework situation, we found that students' background, physiological conditions and the 
Table 3. T-test result.

\begin{tabular}{cccccc}
\hline & \multicolumn{2}{c}{ Leveneru test with equivalent variance } & \multicolumn{2}{c}{ T-test with equivalent mean } \\
\cline { 2 - 6 } & F test & Significance & & F test & Significance \\
\hline Perspective Accuracy & 4.535 & 0.037 & 12.263 & 58 & 0.000 \\
Line Stability & 0.033 & 0.857 & 10.573 & 58 & 0.000 \\
Form Expressivity & 3.392 & 0.071 & 14.242 & 58 & 0.000 \\
\hline
\end{tabular}

aggressive degree affected the tacit knowledge transfer level. In the first stage of the accumulation of knowledge, more aggressive students had better transfer effect. On the other hand, we also found that students who never received basic training in painting in this experiment, clearly transferred better than those who had learned basic painting skills. This also indicates an important factor in the tacit knowledge transfer: if the knowledge had conflict with previous knowledge, it will be less effective in tacit knowledge.

This research analyzes the learning accomplishments in traditional teaching and instruction with Tacit Knowledge Transfer Method (TKTM0). The result indicates that the experiment group (Group A) performs better than the controlled group (Group B) in Perspective Accuracy, Line Stability, and Form Expressivity. Analysis of the experiment results shows that the transferal of tacit knowledge with TKTM can promote performances in "form recognition" and "line stability" significantly, which is different from traditional teaching. Therefore, the application of TKTM is more effective in sketching instruction.

From the experiment results, it shows that the experiment group (Group A) performed better in "Form Expressivity". Therefore, it is suggested that teaching on this subject should be enhanced in order to find out better solutions to promote teaching results. In other words, in the aspect of form expressivity, the students in the experiment group are shown to have made significant progress, with the ability to express form completely, and considerable accomplishment in the transferal of tacit knowledge. The research applied TKTM in sketching instruction. It is helpful to promote students on "perspective accuracy", "line stability", and "form expressivity". Other researchers can extend the results in the study of other arts and craft instruction to maximize its teaching benefit.

\section{Acknowledgements}

This article is partially supported by Ministry of Science and Technology, Taiwan (MOST 103-2221-E-006175-).

\section{References}

Nonaka, I., \& Takeuchi, H. (2004). The Essence of Innovation (with A. Katsumi). Tokyo: Nikkei BP.

Ou, C. J. (2008). A Study on Industrial Design Final Sketches in the Phase of Developing Ideas. Master Thesis, Graduate Institute of Innovation and Design, National Taipei University of Technology.

Polanyi, M. (1967). The Tacit Knowledge Dimension. London: Routledge \& Kegan Paul.

Stewart, T. A. (2002). The Wealth of Knowledge: Intellectual Capital and Twenty-First Century Organization. New York: Currency.

Yi, J. (2006). Wang Qi Yue Recommend Copying Calligraphy (February 10, 2012). 
Scientific Research Publishing (SCIRP) is one of the largest Open Access journal publishers. It is currently publishing more than 200 open access, online, peer-reviewed journals covering a wide range of academic disciplines. SCIRP serves the worldwide academic communities and contributes to the progress and application of science with its publication.

Other selected journals from SCIRP are listed as below. Submit your manuscript to us via either submit@scirp.org or Online Submission Portal.
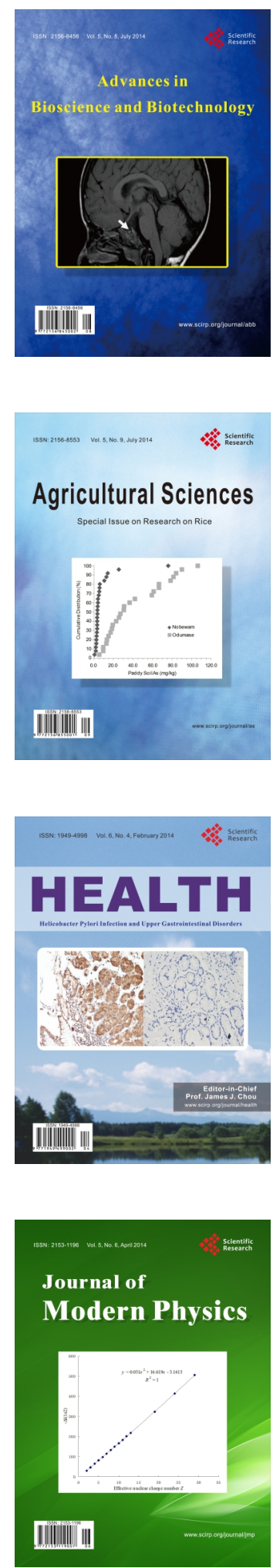
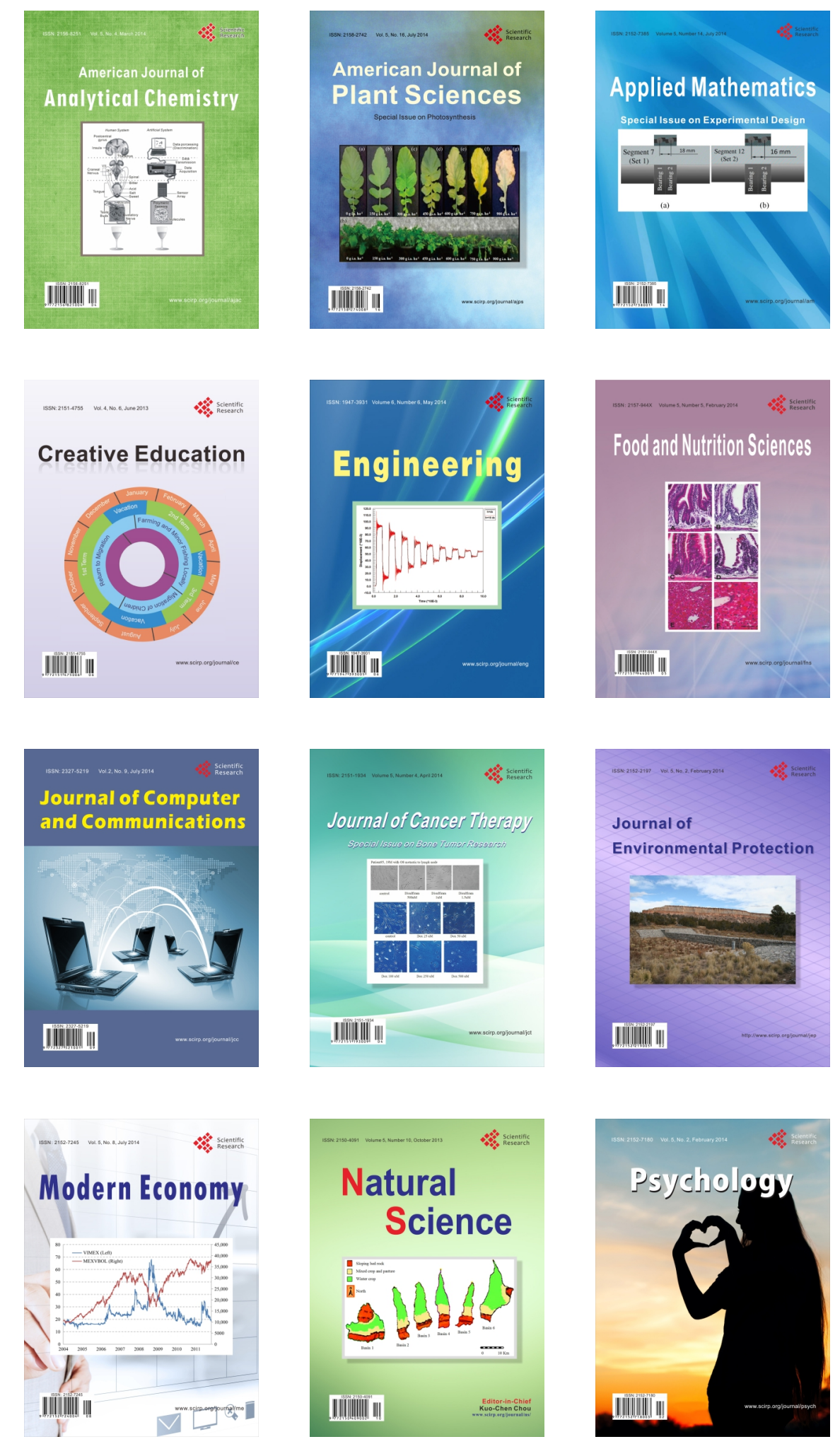